\title{
ESTIMATION OF CO- AND POSTSEISMIC DEFORMATION AFTER THE Mw 8.6 NIAS-SEMEULUE AND Mw 8.5 BENGKULU EARTHQUAKES FROM CONTINUOUS GPS DATA
}

\author{
Wan Anom Wan Aris, Tajul Ariffin Musa, Kamaludin Omar \\ Geomatics Innovation Research Group, Universiti Teknologi Malaysia. \\ anomaris@gmail.com
}

KEY WORDS: GPS, earthquake, postseismic, deformation

\begin{abstract}
:
The Mw 8.5 Bengkulu earthquake of 30 September 2007 and the Mw8.6 28 March 2005 are considered amongst large earthquake ever recorded in Southeast Asia. The impact into tectonic deformation was recorded by a network of Global Positioning System (GPS) Continuously Operating Reference Station (CORS) within southern of Sumatra and west-coast of Peninsular Malaysia. The GPS data from the GPS CORS network has been deployed to investigate the characteristic of postseismic deformation due to the earthquakes. Analytical logarithmic and exponential function was applied to investigate the deformation decay period of postseismic deformation. This investigation provides a preliminary insight into postseismic cycle along the Sumatra subduction zone in particular and on the dynamics Peninsular Malaysia in general.
\end{abstract}

\section{INTRODUCTION}

Large tectonic plate deformations occurred in Southeast Asia on 26th December 2004 due to the $9.2 \mathrm{Mw}$ Sumatra-Andaman earthquake on the subduction zone along the boundary between Australian and Sundaland plates. This megathrust earthquake caused significant co-seismic deformation (from geodetic kinematic results) up to a couple thousand km away from its epicenter (Stein and Okal 2005; Vigny et al. 2005). Peninsular Malaysia, just as many other regions in Southeast Asia such as Sumatra, Java, Thailand, and Myanmar have been coseismically displaced and subsequently undergoing great postseismic relaxation at the centimetre to decimetre level that will probably continue for many years (Satirapod et al. 2013; Panumastrakul et al. 2012; Anugrah et al. 2015; Kreemer et al. 2006).

Although other subsequent large earthquakes of Mw8.6 NiasSemuelue and $\mathrm{Mw} 8.5$ Bengkulu occurred, the internal deformation over the affected area due to large scale of impact in the Southeast Asia. Consequently there are complex ongoing geophysical processes have resulted insignificant post-seismic deformations in several locations in this region. Investigation into the effect of these earthquakes on the distortion of the geodetic reference frame in Malaysia is crucial in order to maintain an accuracy of the active CORS and passive network (i.e, benchmark) that serves as a horizontal datum for surveying and mapping works in the country. Quantification of postseismic model due to aforementioned earthquakes is crucial to account for non-linear distortion of reference frame definition.

This paper presents the utilization of continuous GPS data in Peninsular Malaysia and Sumatra, Indonesia for estimation of postseismic deformation after the occurrence of Mw8.6 NiasSemeulue And Mw8.5 Bengkulu earthquakes. Section 2 describes data selection and methodology to achieve the aim of the study.

\section{DATA AND METHODS OF ANALYSIS}

This section provides discussion on the data selection and methodology for quantifying postseismic deformation in the study area. Figure 1 demonstrates work-flow of the work and description of the work is explained as follows;

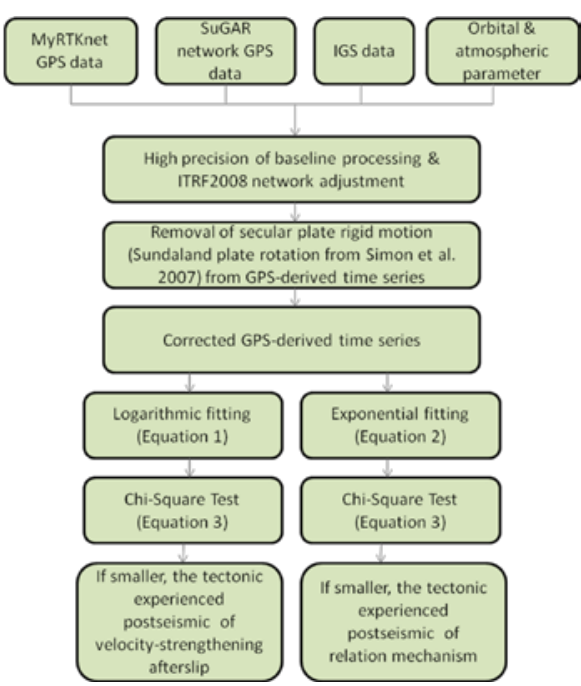

Figure 1. Methodology of the study.

\subsection{GPS Data \& High Precision Time Series Generation}

In Sumatra, Indonesia, five stations of SuGAr network have been deployed in the studies which are LAIS, LNNG, JMBI, ABGS and PBJO. Meanwhile, eight Malaysia Real-time Kinematic Network (MyRTKnet) stations; ARAU, LGKW, SGPT, SBKB, MERU, PDIC, PRTS, and MERS were utilized. Seven years of data period ( $1^{\text {st }}$ January $2005-31^{\text {st }}$ December 2011) have been acquired from Scripps Orbit and Permanent 
The International Archives of the Photogrammetry, Remote Sensing and Spatial Information Sciences, Volume XLII-4/W1, 2016 International Conference on Geomatic and Geospatial Technology (GGT) 2016, 3-5 October 2016, Kuala Lumpur, Malaysia

Array Center (SOPAC) for Sumatran GPS Array (SuGAr) data and Department of Survey \& Mapping Malaysia (DSMM) for the MyRTKnet data. The GPS data has been processed by using high precision processing technique under Quasi-IonosphereFree (QIF) strategy. Geodetic daily positioning solution in term of geocentric cartesian coordinate (x,y,z) were determined for each SuGAr and MyRTKnet stations by connecting the network to the International Terrestrial Reference Frame 2008 (ITRF2008). To this end, minimum constraint approach was performed by the knowledge of thirty-five International GPS Service (IGS) stations distributed all over the earth-crust. Figure2 illustrates the location of the earthquake epicenter and distribution of GPS network used in the study.

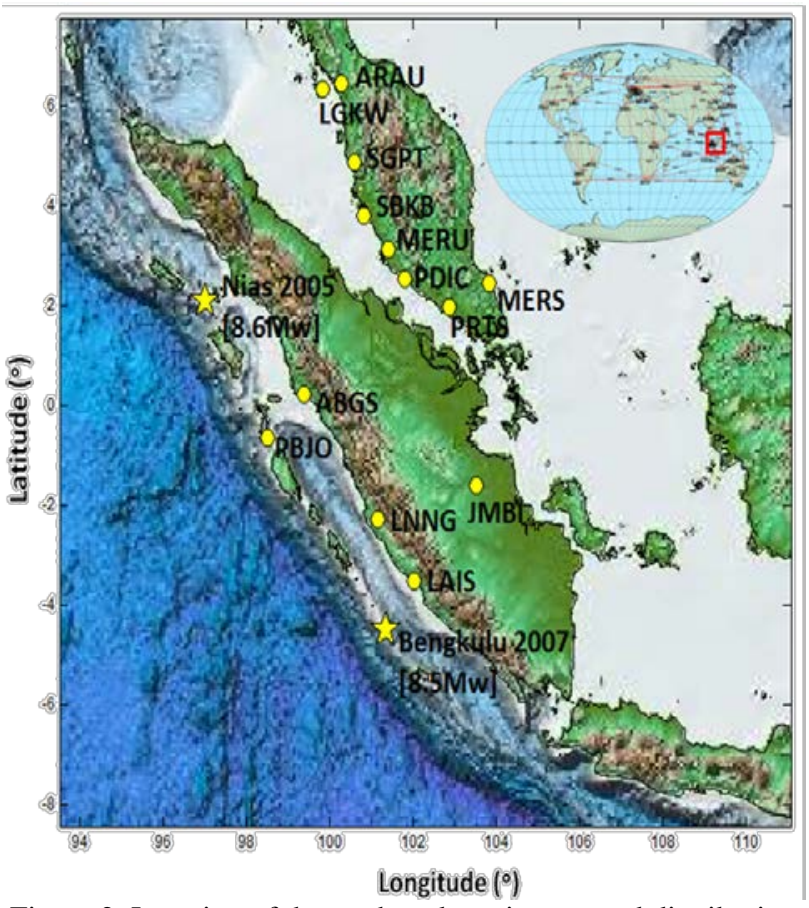

Figure 2. Location of the earthquake epicenter and distribution of GPS network used in the study. Yellow stars are location of earthquake epicenter, while yellow circles are GPS stations utilized in this study.

By following the work by Anugrah et al. (2015), the daily solution of GPS network in ITRF2008 resulted in 4 years of position time series were transformed into ITRF2000 by using helmert-tranformation scheme. This is to allow for obtaining daily solution in Sundaland block by using parameter of rotation pole proposed by Simon et al. (2007). The time series were then plotted using in-house MATLAB programming scheme namely, GRBCRD in order to generate the postseismic time-series for the Nias 2005 and Bengkulu 2007 earthquake event. With the GRBCRD, daily position files in Cartesian coordinates were then converted to local planar coordinate northing and easting in horizontal components and ellipsoidal height (up). This will allow for plotting coordinate time series in both components separately.

The outliers within the time series were then detected by using Auto-Regressive-Moving-Average model (ARMA) technique and removed as it may affect the postseismic deformation trend later for estimating the coseismic offset and deformation parameter after the earthquake.

\subsection{Co- and Postseismic Deformation Parameters Estimation}

A non-linear minimization scheme using least-square estimation method was performed to estimate the postseismic deformation parameter simultaneously. Two types of postseismic process considered independently are; velocity-strengthening afterslip, which follows a logarithmic decay (Kreemer et al, 2006; Marone et al. 1991);

$$
u(t)=c+a \ln \left(1+t / \tau_{\log }\right)
$$

and a relation mechanism, which follows an exponential decay (Kreemer et al., 2006; Savage and Prescott, 1978);

$$
u(t)=c+a\left(1-e^{-t / \tau_{\mathrm{exp}}}\right)
$$

In (1) and (2), $t$ is time since the earthquake, $u(t)$ is the position (north and east), $c$ is the total co- and postseismic offset, $a$ is the amplitude associated with the decay, and $\tau_{\log }$ and $\tau_{\exp }$ are the logarithmic and exponential decay time, respectively (Kreemer et al. 2006). The post-seismic time series were fitted in to the aforementioned deformation function models for both firstorder representations of afterslip and relation process.

\subsection{Statistical Analysis}

Goodness-of-fit statistical test is a method that provides a useful measure of significance of the difference between two models. It was performed to evaluate the suitability of both postseismic processes for the earthquake event and to compares how well two different models fit a set of data. $\chi^{2}$ is a sum of squares of weighted residuals defined as (Stein and Gordon, 1984) as follows;

$\chi^{2}=\sum_{i=1}^{N} \frac{\left(u(t)_{0}(i)-u(t)_{m}(i)\right)^{2}}{u(t)_{m}(i)}$

Where $u(t)_{0}$ is the observation position of site $i, u(t)_{m}$ is the calculated position of site $i$ from the postseismic model (logarithmic or exponential function models), and $N$ is the total number of observations. A good model should have a minimum reduced $\chi^{2}$ which indicates the best fitting of deformation model estimation.

\section{RESULTS AND ANALYSIS}

From the high-precision processing of daily solutions between years 2005 and 2011 ambiguity resolution showed results above $75 \%$. Positional root-mean-square (rms) errors for all stations were below $1 \mathrm{~mm}$ for the horizontal component and between $1 \mathrm{~mm}$ and $1.5 \mathrm{~mm}$ for the height component.

The time series for ongoing Sumatra-Andaman earthquake as detected by twelve GPS stations of SuGAr and MyRTKnet is illustrated in Figure 2. The estimated geodetic coseismic offsets and postseismic amplitudes for the earthquake range between stations from several centimeters to millimeters. The location of PBJO, LNNG, LAIS ABGS and JMBI stations are much closer to the rupture of both earthquakes. Thus the 

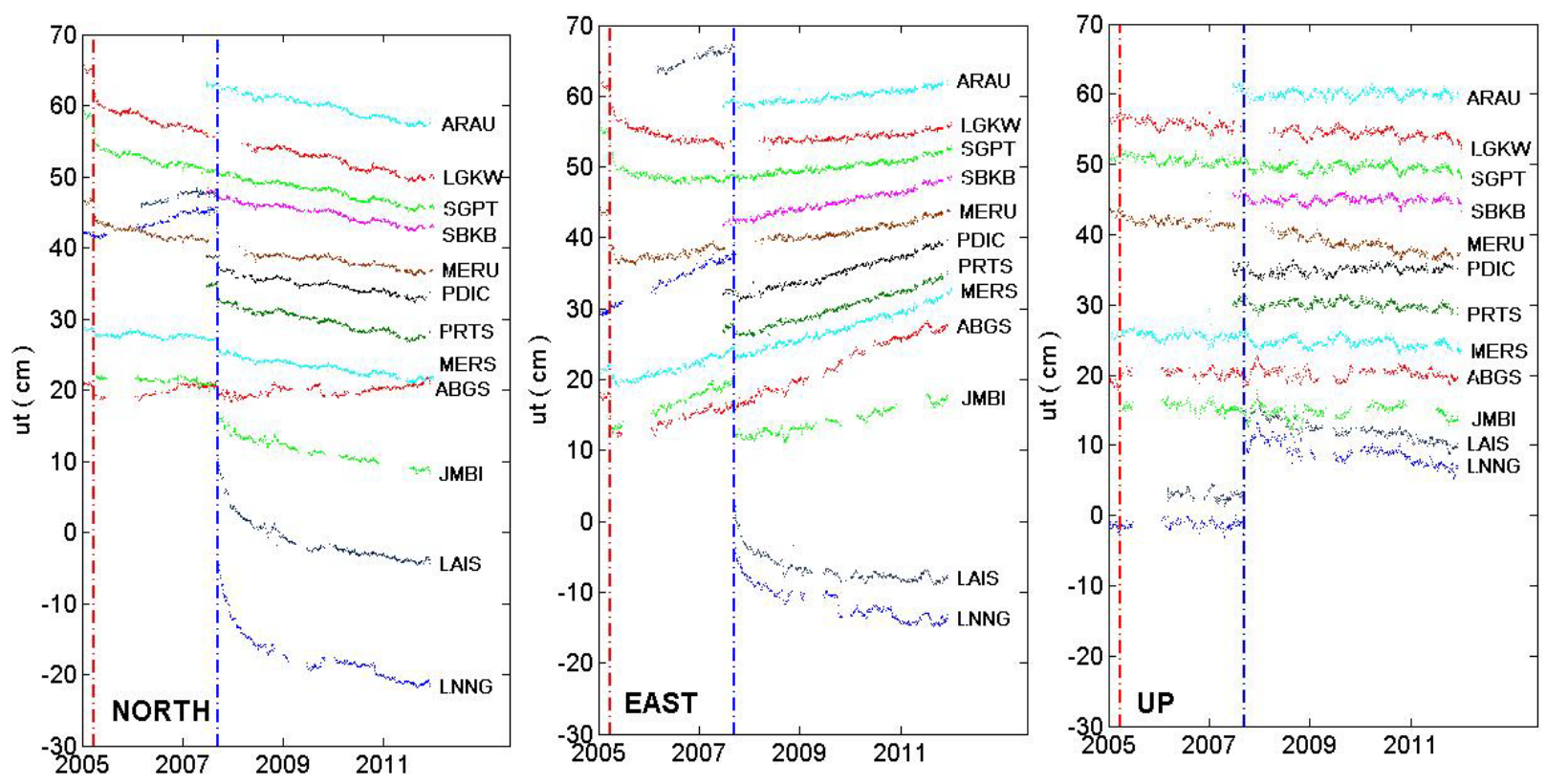

Mw=8.6 NIAS EQ

------ Mw=7.9 BENGKULU EQ

Figure 3. Coordinate time series (associated with linear Sundaland rigid plate $\mathrm{m}$ and postseismic motion) for the 12 GPS stations in three separated planar components; north, east and up directions.

deformation estimation was separated into two part; southern of Sumatra and west-coast of Peninsular Malaysia. With each postseismic deformation models, the result has found that, the time of decay in southern Sumatra since the day of Nias 2005 earthquake is $116 \pm 0.1$ days for logarithmic decay model and $989 \pm 0.1$ for exponential decay.

For earthquake of 2007 Bengkulu, the deformation has taken for about $1219 \pm 0.1$ days for logarithmic decay model and $451 \pm$ 0.1 days for exponential decays. Meanwhile, along the westcoast of Peninsular Malaysia experienced postseismic after the Nias 2005 earthquakes with logarithmic and exponential decays at $851 \pm 0.1$ days and $1119 \pm 0.1$ days, respectively. Meanwhile, the region felt another deformation decays after Bengkulu 2007 earthquakes for about $311 \pm 0.1$ days and $219 \pm 0.1$ days for logarithmic and exponential functions.

Goodness-of-fit test for both deformation models indicates that, the postseismic time-series are fit significantly better by logarithmic decay model than exponential decay model. The averaged goodness-of-fit results in averaged chi-square term at 3.2 and 69.3, respectively. Thus, logarithmic decay deformation is considered which indicates velocity-strengthening afterslip for both this event. However, the results indicate first-order of post-seismic and viscoelastic relation for continuous GPS data of 100 days forward has to be taken into account.

According to Figure 3 coseismic offsets were detected up to $\sim 2$ metre at ABGS can be depicted from the study. In contrast, coseismic subsidence was observed from a few millimeters to 1 meter along the fore-arc region. The study also found that sites in the west-coast of Peninsular Malaysia also have the largest coseismic displacement as compared to the east-coast side. A noticeable post-seismic deformation as experienced by both Peninsular Malaysia and Sumatra after 1000days from the earthquake day was identified. The deformation towards the rupture are, was likely affected by double coseismic and postseismic deformations recent megathrust earthquakes. Site of UMLH in northern Sumatra maintained similar postseismic horizontal directions after the 2004 earthquake however greater vertical deformation at $\sim 6 \mathrm{~cm}$ per year can be identified which moving reversed from co-seismic subsidence to postseismic uplift.

On contrary, sites LNNG and PBJO in southern Sumatra moved to northeast direction and experienced slow vertical deformation at $\sim 2 \mathrm{~cm}$ per year. Despite the postseismic deformations in Sumatra, crustal deformation over Peninsular Malaysia moved heterogeneously over latitudinal directions. The postseismic motion in the northern parts shows horizontal deformation at $\sim 2-3 \mathrm{~cm}$ per year which $\sim 40$ percent greater than one that observed by the sites in the middle and southern part. However, slow rates of vertical component were found of the region. The crustal deformation characteristic during the period indicated that there are cumulative post-seismic deformations driven by the 2004 Sumatra-Andaman and 2005 Nias Simuelue earthquakes. This phenomenon was also seen by sites in southern Thailand (Panumaskul et al. 2012).

A widespread of coseismic trench ward motions due to Bengkulu earthquake were identified by sites in Sumatra, and Peninsular Malaysia. Large cosesimic were found reaching $\sim 1.8 \mathrm{~m}$ at site LNNG and LAIS. The sites situated along the strike from megathrust rupture moved several millimeter to centimeters away from the rupture source. Besides, vertical uplift motion at sites ABGS and LNNG were observed at $5 \mathrm{~mm}$ to $19 \mathrm{~cm}$. On contrary site JMBI experienced almost zero vertical change. Approximately $1000 \mathrm{~km}$ from the rupture zone, large coseismic at $\sim 5 \mathrm{~cm}$ were depicted at sites of southern Peninsular Malaysia. This offset resulted by the earthquake shows a newly deformation orientation the crustal in the area thus complicate to model the long-term postseismic in Peninsular Malaysia. However the cumulative post-seismic displacements by end of 2011 were smaller than the co-seismic 
displacements at most station, except for sites in the northwest of Peninsular Malaysia such as LGKW and ARAU. The postseismic horizontal displacements continued in a direction similar to the co-seismic displacements. Overall, larger magnitude size of earthquakes in southern Sumatra gave a significant impact into tectonic deformation in Peninsular Malaysia.

\section{CONCLUDING REMARK}

This paper show that GPS sites in northern Sumatra and westcoast of Peninsular Malaysia is clearly enabled to estimate the duration of postseismic process. The results from the test indicates that the GPS data in northern Sumatra and west-coast of Peninsular Malaysia for the period of seven years since the day of Nias 2005 and Bengkulu 2007 earthquake are fit better using logarithmic function. The results have concluded that GPS data for a period of 2005-2012 are indicates that the region is experiencing velocity-strengthening afterslip.

As for revising new reference frame realization in Malaysia, this finding is suggested to be considered in order to determine the postseismic model to cope non-linear tectonic change within the region. This study also intended to maintain continuous GPS data for further hazard analysis within the region.

\section{ACKNOWLEDGEMENTS}

The author wish to thank the Department of Survey \& Mapping Malaysia (DSMM), SOPAC and IGS for providing the GPS data.

\section{REFERENCES}

Anugrah B., Meilano, I., Gunawan, E., Efendi, J., (2004), Estimation of postseismic deformation parameters from continous GPS data in northern Sumatra after the 2004 Sumatra-Andaman earthquake.

Kreemer, C., G. Blewitt, W. C. Hammond, and H.-P. Plag (2006), Global deformation from the Great 2004 SumatraAndaman earthquake observed by GPS: Implication for rupture process and global reference frame, Earth Planets Space, 58 (141-148).

Marone, C. J., C., H. Scholz, and Bilham (1991), On the mechanics of earthquake afterslip, J. Geophys. Res., 96, 84418452.

Satirapod, C., Trisirisarayawong, L, Fleitout, J.D. Garaud, and Simons W.J.F. (2013) Vertical motions in Thailand after the 2004 Sumatra-Andaman earthquake from GPS observations and its geophysical modeling, Adv. Space Res., 51(8), 1565-1571, doi:10.1016/j.asr.2012.04.030.

Savage, J.C., and W.H. Prescott (1978) Asthenosphere readjustment and the earthquake cycle, J. Geophy, Res., 83, 3369-3376.

Simons, W. J. F, Socquet, A., Vigny, C., Ambrosius, B. A. C., Abu, S.H., Promthong, C, Subarya, C., Sarsito, D. A., Matheussen, S., Morgan, P. and Spakman, W., (2007), A
Decade of GPS in Southeast Asia: Resolving Sundaland motion and boundaries. J. Geophys. Res: Solid Earth (1978-2012) 112(B6):1-20.

Stein, S.\& Okal, E. (2005) Speed and size of the Sumatra earthquake. Nature 434,581--582.

Panumastrakul E., Simons, W. K. F., Satirapod, C., (2012), Modelling post-seismic displacement in Thai geodetic network due to the Sumatra-Andaman and Nias earthquakes using GPS observations, Survey Review Ltd 2012., doi: 10.1179/1752270611Y.00000000017.

Vigny, C., Simons, W.J.F., Abu, S., Bamphenyu, R., Satirapod, C., Choosakul, N., Subarya, C., Socquet, A., Omar, K., Abidin, H.Z., Ambrosius, B.A.C., (2005) Insight into 2004 SumatraAndaman earthquake from GPS measurements in southeast Asia. Nature, 436, 201-206, doi:10.1038/nature03937. 